\title{
ANTÍGONA Y ARISTÓTELES: UNA LECTURA A DOS VOCES ACERCA DE LA AMBIGÜEDAD DE LA TÉCNICA
} ANTIGONE AND ARISTOTLE: INTERPRETING TWO VOICES ON THE AMBIGUITY OF THE TECHNIQUE ANTÍGONA E ARISTÓTELES: UMA LEITURA A DUAS VOZES SOBRE A AMBIGUIDADE DA TÉCNICA

Joaquín García-Huidobro'

Constanza Giménez²

Diego Honorato ${ }^{3}$

\section{Resumen}

En el "Canto al hombre", recogido en Antígona, Sófocles puso de relieve la ambigüedad moral de la técnica. Ya que puede ser usada tanto para bien como para mal, requiere una orientación superior, representada por las leyes divinas. Este tema es retomado por Aristóteles, aunque sobre bases seculares, con su idea de que hay cosas que son justas o injustas por naturaleza. Para él, la recta orientación de la técnica no depende primeramente del conocimiento de ciertas reglas éticas, sino de la formación del carácter, ya que el conocimiento del bien depende de las disposiciones morales del sujeto.

Palabras clave: relativismo ético, técnica, Sófocles, Antígona, Aristóteles (Fuente: DeCS, Bireme).

DOI: 10.5294/PEBI.2015.19.2.9

\section{PARA CITAR ESTE ARTíCULO / TO REFERENCE THIS ARTICLE / PARA CITAR ESTE ARTIGO}

García-Huidobro J, Giménez C, Honorato D. Antígona y Aristóteles: una lectura a dos voces acerca de la ambigüedad de la técnica. pers.bioét. 2015; 19(2): 303-318. DOI: 10.5294/pebi.2015.19.2.9

1 Doctor en Filosofía. Universidad de los Andes, Chile. jgh@miuandes.cl.

2 Doctora en Filosofía. Universidad de los Andes, Chile. constanza.gimenez@gmail.com.

3 Doctor en Filosofía. Universidad de los Andes, Chile. dhonorato@uandes.cl. El autor agradece el patrocinio de Fondecyt (proyecto n. 1130365).

FECHA DE RECEPCIÓN:

FECHA DE ENVÍO A PARES:

FECHA DE APROBACIÓN POR PARES:

FECHA DE ACEPTACIÓN:
2015-05-28

2015-05-28

2015-08-28

2015-09-16 


\section{Abstract}

In the "Ode to Man," in Antigone, Sophocles stressed the moral ambiguity of the technique. Since it can be used for both good and bad, it requires a higher guidance, one represented by divine law. This theme is taken up by Aristotle, but on a secular basis, with his idea that some things are right or wrong by nature. For Aristotle, the straight orientation of the technique does not depend primarily on knowledge of certain ethical rules, but on the formation of character, since knowledge of what is good depends on the moral disposition of the subject.

KeYwords: Ethical relativism, technique, Sophocles Antigone, Aristotle (Source: DeCS, Bireme).

\section{Resumo}

No "Canto ao homem", coletado em Antígona, Sófocles ressaltou a ambiguidade moral da técnica. Como pode ser usada tanto para bem quanto para mal, requer uma orientação superior, representada pelas leis divinas. Esse tema é retomado por Aristóteles, embora sobre bases seculares, com sua ideia de que há coisas que são justas ou injustas por natureza. Para ele, a reta orientação da técnica não depende primeiramente do conhecimento de certas regras éticas, mas sim da formação do caráter já que o conhecimento do bem depende das disposições morais do sujeito.

Palavras-chave: relativismo ético, técnica, Sófocles, Antígona, Aristóteles (Fonte: DeCS, Bireme). 
Uno de los momentos más interesantes de la historia de la humanidad ha sido, sin duda, el siglo de Pericles en Atenas (s. IV a. C.), que no en vano ha sido llamado el "Siglo de Oro" de la antigua Grecia. En efecto, si consideramos su legado en el campo de la literatura, la arquitectura, la filosofía y muchas otras expresiones de la cultura, nos impresiona la fuerza creadora de aquella edad que constituye uno de los puntos culminantes de la aventura humana. Sin embargo, no debemos olvidar que gran parte de esas magníficas obras que hoy admiramos no tuvieron un origen ni un contenido pacíficos: fueron el fruto de polémicas intelectuales que permanecen hasta la actualidad. Sobre todo debemos atender a la conmoción intelectual provocada por la irrupción de los sofistas ${ }^{4}$ en el escenario cultural ateniense y sus provocativas propuestas, que van desde el evolucionismo, el progresismo y la crítica de la religión hasta el relativismo moral. ${ }^{5}$ Las reacciones que provocó este movimiento fueron diversas, pero las más conocidas en el terreno filosófico fueron las de Sócrates, Platón y Aristóteles. Sin embargo, esta polémica irrumpe mucho antes en el campo literario de un modo fundamental y profundo, concretamente en el género de la tragedia, una de cuyas figuras principales fue Sófocles, quizás el mayor de los autores trágicos. A pesar de que solo se conservan siete de las 123 tragedias que escribió, estas nos proporcionan material suficiente como para percibir que algunas de sus obras contienen un claro fin pedagógico y de tonalidad

4 Conviene aquí recordar que la primera generación de sofistas, representada por Protágoras y Gorgias, estaba plenamente activa en el 442, fecha del estreno de Antígona. Diógenes Laercio, por ejemplo, establece el apogeo o floruit de Protágoras en la 84 olimpiada (444-441 a. C.). Cf. Diógenes Laercio, Vidas de los filósofos ilustres, 9. 8.

5 Para una descripción de este ambiente intelectual, véase Guthrie (1). abiertamente polémica, aunque su autor nunca fue un reaccionario frente al orden social de su tiempo. Estas expresan, sobre todo, las graves consecuencias que trae consigo el abandono del orden tradicional — propuesto, precisamente, por los sofistas- , tanto en el plano de lo divino como en el de la moralidad.

En las páginas que siguen comentaremos un texto de Sófocles que ha sido objeto de cierta atención en los últimos 100 años: ${ }^{6}$ nos referimos al "Canto al hombre", incluido en su célebre obra, Antígona. ${ }^{7}$ En este contexto, analizaremos el problema de la ambigüedad moral de la técnica y la posición asumida por Sófocles en relación con este. En segundo lugar, describiremos en sus líneas principales la posición secularizada que Aristóteles propugna frente a esta misma cuestión. Por último, expondremos las diferencias y similitudes de ambos planteamientos a partir de un análisis comparativo entre la Antígona de Sófocles y la ética aristotélica.

\section{"CANTO AL HOMBRE": LA SINGULARIDAD DEL SER HUMANO}

La principal discusión que subyace a la tragedia Antígona es la correspondiente a los límites del poder político. En efecto, la protagonista, Antígona, cuestiona el valor del decreto de su tío y rey, Creonte, quien ha ordenado que Polinices, hermano de Antígona, sea privado de sepultura como castigo por su alianza con los argivos, tradicionales enemigos de Tebas.

6 Por ejemplo, véanse Heidegger (2) y Patocka (3).

7 Las traducciones del coro y de otros pasajes tomados de Antígona pertenecen al profesor, y coautor del artículo, Diego Honorato. Se sigue la edición alemana a cargo de N. Zink, Sophokles (4). 
Consideremos a continuación el contexto del pasaje que nos ocupa, el "Canto al hombre", presente en el segundo estásimo de la tragedia. Este consiste en una intervención del coro destinada a exaltar la habilidad y el ingenio humanos. ${ }^{8}$ Sin embargo, al mismo tiempo, introduce una pausa en el intenso curso de la tragedia, que ha alcanzado un alto nivel de tensión dramática, tanto por la discusión entre Antígona y su hermana Ismena (acerca de cómo proceder ante el edicto real que prohíbe dar sepultura a Polinices) como por el conocimiento del rey acerca de que alguien (en los hechos, Antígona) ha rendido honras fúnebres a su difunto sobrino, transgrediendo su expresa prohibición. Esta pausa induce a los espectadores a reflexionar acerca de los límites del poder humano y de los instrumentos que este ha desarrollado para imponer su dominio sobre el cosmos.

El coro comienza aludiendo al carácter único del hombre. En efecto, entre todas sus impresionantes facetas, la más admirable (deinós) es precisamente esta condición única que lo diferencia del resto del cosmos. Ella se aprecia en su capacidad de surcar los océanos y de cultivar la tierra para arrancarle todos los años sus cosechas. En este punto cabe una aclaración fundamental en relación

8 La relación entre el hombre y la técnica fue objeto de una reflexión por parte de los griegos desde tiempos homéricos, donde normalmente la téchnē equivalía a adquirir una determinada habilidad (p. ej., el arte de la herrería de Hefesto; véase la Ilíada, 1.571; 18.143). Por otra parte, ya en el Himno Homérico a Hefesto (circa. s. VII a. C.) encontramos una valoración de la técnica como poder de dominio sobre la naturaleza. En un tono similar, y muy próximo ya al "Canto al Hombre" de Antígona, la tragedia de Esquilo Prometeo Encadenado (cfr. 448-486) es un antecedente fundamental. En este sentido, el texto de Sófocles que comentaremos a continuación se instala al interior de un discurso acerca de la técnica que no era en absoluto ajeno a la cosmovisión griega. Puede encontrarse una breve reseña histórica de estos elementos en Angier (5). con el sentido del texto: el dominio del hombre sobre la naturaleza no posee aquí el sentido de algo perturbador o terrible, sino de asombro o admiración frente a su pasmosa superioridad. Esta línea interpretativa (asumida por gran parte de las traducciones españolas, francesas e inglesas) se ve claramente confirmada en la primera antistrofa por el epíteto que Sófocles aplica al hombre, y que en gran medida resume el sentido de los versos anteriores: del hombre, que domina con su inteligencia los mares, la tierra y los animales, se nos dice que es "hábil" o "inteligente" (perifradès anèr). ${ }^{9}$ En efecto, oímos entonar al coro:

Muchas cosas hay admirables [deiná], pero ninguna más admirable [deinóteron] que el hombre. Este viaja hasta el otro lado del ponto resplande-

9 La palabra griega deinós posee dos campos semánticos diversos, pero afines entre sí. Por una parte, significa "que causa temor" "espantoso" o "terrible"; por otra, significa "extraño", "maravilloso” o "admirable”. En español, Vigo y Pinkler (6) traducen "terrible" en una lectura que se remonta a la interpretación de M. Heidegger, quien en su Introducción a la Metafísica (2) lee unheimliche (inquietante, perturbador, siniestro). Esta lectura, a su vez, tiene un antecedente fundamental en Hölderlin, quien tradujo ungeheuerer (monstruoso, desmesurado, tremendo). Aunque la interpretación de Heidegger, en la línea de Hölderlin, es ciertamente tentadora al captar la ambigüedad intrínseca de la técnica, nos parece, sin embargo, errónea desde un punto de vista textual. En ninguna parte del texto resuena aquí lo "monstruoso" del dominio humano. Por otra parte, en el texto es explícita la conexión entre deinós y perifradēs. En efecto, uno de los usos más corrientes del término deinós (en una construcción muy usual que toma infinitivo o acusativo) alude a la capacidad de ser "hábil para algo", con especial énfasis en una habilidad práctica (y en ocasiones opuesto a sophós). Para la oposición entre sophós y deinós, en el sentido de habilidad práctica, cfr. Platón (7); también véase deinòs légein, "hábil para hablar", en Apología, 17b 3; o la expresión deinós tèn téchnèn, diestro para un arte o técnica, en Aristófanes (8). 
ciente en medio del tempestuoso viento del sur, lo atraviesa envuelto por el henchido oleaje. Y a la más poderosa de entre los dioses, a la Tierra, indestructible e infatigable, él la consume, año tras año, abriéndole surcos con los arados, labrándola con el mulo (vv. 332-341) [Estrofa 1].

Este dominio se extiende a las aves y a las fieras: el hombre captura los peces que habitan en las profundidades y es capaz de engañar y domesticar a los animales:

Al género de los sencillos pájaros, a las manadas de animales salvajes y a las criaturas marinas del ponto, las atrapa ciñéndolas con sus redes entretejidas de hilo, el hábil hombre [perifradēs $a \bar{e} r]$. Con sus tretas [mēchanais] domina a la agreste bestia que ronda por los montes, y al caballo de greñudo pelo le unce firme el yugo alrededor del cuello, e igualmente al infatigable toro de las montañas (vv. 342-351) [Antistrofa 1].

Una vez realizada esta caracterización del poderío humano, el coro procede a mostrar lo específico del hombre, es decir, el lenguaje, el pensamiento y el orden cívico o social. Ahora bien, estos son, ciertamente, atributos naturales del hombre pero, al mismo tiempo, constituyen una obra suya. En efecto, por medio de la forma media (reflexiva) del verbo didáskomai (aprender por uno mismo), Sófocles expresa que el hombre se enseñó a sí mismo, tanto en lo relativo a sus capacidades cognoscitivas y expresivas como en lo que respecta al ordenamiento de las inclinaciones o tendencias (orgás) que regulan la práxis pública (astunómous). En este punto resulta sumamente interesante destacar que, a diferencia de la tradición anterior, que solía pensar estos atributos como regalos divinos ${ }^{10}$ Sófocles los presenta, en cambio, como logros humanos. Aquí se deja entrever una primera forma de ilustración o secularización que viene a confirmar el lugar estratégico (intermedio) que ocupa Sófocles en la literatura del siglo de oro ateniense. Desde esta perspectiva, en Sófocles —al igual que en Esquilo- se encontraría un respeto esencial por la tradición y por aquel tiempo originario del cual aún resuenan "las firmes leyes orales [ágrapta: no escritas] de los dioses" (v. 454). Sin embargo (como ha hecho ver Leandro Pinkler), se percibe también en Antígona —y especialmente en el pasaje que nos ocupa - una necesidad de apertura hacia esas "nuevas ideas del humanismo laicista" (10), de cara a reformular (y no a cambiar) la antigua tradición. Según esta interpretación, Sófocles nos enseña a escuchar y a guardar cuidadosamente la memoria del pasado, pero manteniendo la mirada en el presente y en lo que está por venir. Esta posición — como se verá en la segunda parte del presente artículo_- asume, al menos en parte, el movimiento ilustrado de los sofistas ${ }^{11}$ y entronca con extraordinaria precisión con el tipo de reflexión que Aristóteles desarrollará siglos más adelante.

10 En la tradición griega es Prometeo, quien al robarle el fuego a Zeus, le confiere también al hombre el sentido de socialización, y con este, el lenguaje, la técnica y la cultura en general. Cfr. Platón (9); véase también el mito de Thamus y Theuth en el Fedro platónico, donde nuevamente la escritura se revela como un regalo divino.

11 "En parte". Ciertamente, no será hasta Eurípides que la tragedia asuma plenamente el pensamiento sofista. Sófocles, como hemos advertido, ocupa un lugar intermedio entre el tradicionalismo de Esquilo y el progresismo de Eurípides. Siguiendo esta misma lógica, lo decisivo en Antígona consiste en la adecuada articulación entre los preceptos tradicionales de los dioses (Thémis o Díke) y la ley humana (nómos). 


\section{SÓFOCLES NOS ENSEÑA A ESCUCHAR Y A GUARDAR CUIDADOSAMENTE LA MEMORIA DEL PASADO, PERO MANTENIENDO LA MIRADA EN EL PRESENTE Y EN LO QUE ESTÁ POR VENIR.}

Retomemos, pues, el análisis del coro: esta vez se trata de la segunda parte de la estrofa recogida. Aquí, el autor resalta que si el hombre puede huir del frío, de la lluvia y de tantas calamidades, esto se debe a que él es "todo recursos", de modo que puede escapar de todos —o de casi todos- los males:

Tanto el lenguaje como el ágil pensamiento y la inclinación a respetar el orden social se enseñó a sí mismo [edidáxato]. Y de los dardos de las inhóspitas heladas bajo el cielo descubierto y de las amenazantes tormentas aprendió a huir, (él) (que es) todo recursos [pantopóros]. Y sin recursos nada de lo que está por venir enfrenta. Tan solo del Hades no hallará escapatoria, pues aun para males invencibles él ha ideado (junto a otros) [sym-péphrastai] soluciones (vv. 353-363) [Estrofa 2].

Hasta este punto, las palabras de Sófocles bien podrían pertenecer a las de un sofista que, como Protágoras, proclama que "el hombre es la medida de todas las cosas" (7). Pero esto es solo en apariencia. Recordemos que la exaltación precedente que hemos observado en el texto acerca de las grandezas del hombre no ha hecho más que preparar el terreno para una observación crítica del todo ausente en la reflexión - de tipo optimistapropia de los sofistas: el hombre puede escapar de todos los males, pero es inerme ante la muerte. La muerte constituye un límite absoluto. De aquí se siguen varias observaciones: en primer lugar, si la muerte es un límite irremediable, ningún progreso técnico, incluidos los de carácter médico, logrará derrotar definitivamente la enfermedad y la muerte. El hombre no es señor sobre la muerte, como bien lo determinó Hipócrates, un contemporáneo de Sófocles, en su célebre juramento (11). Pretender lo contrario, expresa Sófocles, no es más que arrogancia, hýbris, como la de Ícaro y Dédalo. En segundo lugar, la propia historia de Antígona manifiesta el hecho central de que no le corresponde a ningún rey de la tierra disponer sobre el destino de los muertos. La muerte está más allá de lo humano, es territorio de los dioses, quienes castigan al que pretende enseñorearse sobre esta.

Pero el hecho de que la muerte constituya una frontera absoluta, tiene también una importante consecuencia cuando se trata de determinar el propio modo de vida, es decir, tiene consecuencias en el campo de la moral. En este punto, cabe señalar como primer aspecto que, tradicionalmente, una de las mayores manifestaciones de la dignidad del hombre ha sido su conciencia de la muerte. Esta conciencia lo pone en condiciones de conducir su existencia de cara a este hecho fundamental. A este respecto, vemos que, en su discusión con Ismena - la hermana que por temor a recibir el castigo dictaminado por Creonte se negaba a enterrar a Polinices-, Antígona pone ante sus ojos el hecho de que, si todos vamos a morir, es preferible hacerlo por un motivo justo. Si se trata de complacer a alguien, ella prefiere ser grata "a los de abajo" (v. 75), es decir, a los muertos, más que al pueblo o a los poderosos de la tierra: "Y para mí morir 
realizando esta tarea es algo hermoso. Yaceré, querida, junto a él, junto a quien quiero, habiendo osado cometer un crimen santo" (vv. 72-74).

Después de aludir a la frontera representada por la muerte, el coro prosigue enalteciendo el poder humano y su inteligencia, pero expresando, a la vez, que tal sabiduría debe alimentarse de una fuente supraterrena. No en vano, en el contexto de su discusión con Creonte, Antígona invoca la existencia de otra legalidad, inmemorial y superior, que ordena dar sepultura a los muertos (10), frente a la cual los edictos del rey carecen de todo valor. En efecto, canta el coro:

Poseyendo un ingenio [sophón] más allá de toda expectativa para idear soluciones técnicas [téchnas]; unas veces hacia el mal, otras veces hacia el bien conduce "esta habilidad". Pues al honrar las leyes [nómous] de la tierra y la justicia $[$ díkan] de los dioses, a la que está obligado bajo juramento, será estimado por la ciudad [hupsípolis]; mas aquel que, por causa de su temeridad, tome parte en lo que no es bueno, quedará proscrito de la ciudad [ápolis]. ¡Qué no llegue a sentarse cerca del fuego de mi hogar, ni tenga pensamientos como los míos quien estas cosas realice! (vv. 364-375) [Antistrofa 2].

Hemos llegado a un punto central de la reflexión que plantea Antígona. Mientras que los sofistas, en su visión progresista de la historia, consideraban la técnica como el instrumento que llevaría al hombre a una situación muy superior con respecto de la actual, el coro nos recuerda aquí que la técnica es ambigua: a veces se dirige al bien y otras al mal. Si la técnica no necesariamente representa un bien —ya que puede ser utilizada contra el hombre- entonces no puede constituir un criterio último de acción. Para que lo fuera, el progreso técnico tendría que coincidir necesariamente con el progreso humano. De modo que esta requeriría de otros criterios que la dirijan y orienten.

Ahora bien, si volvemos nuestra atención sobre la antistrofa 2 , resulta llamativa la aparente discontinuidad que existe entre los primeros dos versos y el tercero. El primer verso funciona como una síntesis de todo lo expresado: el hombre ocupa un lugar singular en el cosmos, pues tan solo él posee una inteligencia práctica o un ingenio [sophón] que lo capacita para idear soluciones técnicas para todos (o casi todos) sus problemas. Luego, en el verso dos, se nos advierte en perfecta continuidad con lo anterior sobre un riesgo esencial a tal habilidad, esto es, la posibilidad intrínseca de hacer buen o mal uso de la misma. Hasta aquí todo está claro. Sin embargo, ¿por qué razón el coro, realizando un aparente giro en la argumentación, nos refiere de pronto, sin ninguna transición, a la necesidad del hombre de respetar tanto la ley humana (nómos) como la ley divina (díkē)? ¿Cuál es la relación entre el buen o mal uso de la técnica y la necesidad humana de honrar la ley? Aunque no haya más indicaciones en el texto, la respuesta nos parece evidente: porque la técnica humana, en tanto que acción (productiva), no puede sino estar sujeta a leyes terrenas que, a su vez, están atadas a la justicia originaria de los dioses a la que nos remite la tradición oral. Por ello, solo sabrá hacer un uso correcto de la técnica quien, honrando las leyes humanas, honre también la ley divina, en cuanto que esta opera como objeto último y fundamento de la anterior.

Estas consideraciones, sin embargo, requieren todavía de una precisión ulterior. Efectivamente, en virtud de su 
ordenamiento al hombre, la técnica supone también una consideración importante respecto de la pólis, es decir, del ordenamiento de lo público. Volvamos a leer esos decisivos versos: "Pues al honrar las leyes [nómous] de la tierra y la justicia [díkan] de los dioses, a la que está obligado bajo juramento, será estimado por la ciudad [hupsípolis]; mas aquel que, por causa de su temeridad, tome parte en lo que no es bueno, quedará proscrito de la ciudad [ápolis]".

En este pasaje, la necesidad de honrar tanto las leyes humanas como las leyes divinas aparece como una condición indispensable para llegar a ser hupsípolis, es decir, honrado o tenido en estima por la ciudad. Mas, quien se deje llevar por su osadía menospreciando las leyes humanas y divinas, quedará ipso facto fuera del ordenamiento público. Será ápolis, alguien carente del sentido de lo político: un forajido, un proscrito o, como nos señala Aristóteles en el libro I de la Política, un "amante de la guerra", "una pieza aislada en los juegos” (1253a9-10). En efecto, como señala Fanny Söderbäck (12) — siguiendo la interpretación de Hannah Arendt (13)—, Creonte (representante de la tiranía) no distingue la esfera pública de la privada ni de la divina. Se atreve a dictaminar frente a los muertos y además realiza de manera privada y personal acciones que debieran ser públicas: manda enterrar en vida a Antígona, de modo que nadie podrá ser testigo de su muerte (12). Tampoco se responsabiliza de esta muerte, porque hace recaer en Antígona la decisión de vivir enterrada o bien de suicidarse. Su actuar es inconsistente y antipolítico al obrar en soledad (y no en comunidad), hecho del que lo acusa su hijo Hemón: "Hemón: —La ciudad no es algo que le pertenezca a un solo hombre.
Creón: - ¿ $Y$ Y no se considera que la ciudad es de quien ejerce el poder? Hemón: — Tú gobernarías con justicia tan solo una tierra desierta" (vv. 737-739). ${ }^{12}$

Siguiendo esta misma línea, podemos hacer la siguiente reflexión: las formas poiéticas del saber humano, donde situamos de un modo general a la téchnē, no solo estarían sujetas al perfeccionamiento del individuo (por ejemplo, para ampliar una habilidad), sino que poseerían también una connotación social y comunitaria, puesto que ellas pueden ser orientadas tanto hacia el mal como hacia el bien ["unas veces hacia el mal, otras veces hacia el bien" v. 365]. Disyuntiva frente a la cual Sófocles advierte severamente sobre la necesidad de que el saber técnico respete las leyes humanas y las divinas si quiere ser

12 "No te aferres a ti mismo ni a una sola manera de ver las cosas, aquella que tú dices ser la correcta, y a ninguna otra más, pues aquel que piensa que solo él posee sensatez, el don de la palabra o inteligencia, y ningún otro, se expone a ser considerado como un hombre vano y superficial" (vv. 705-709).

Siguiendo el concepto de acción desarrollado por Hannah Arendt (13), Söderbäck (12) señala que Creonte no actúa, sino que usa la violencia. La acción de Creonte no solo es autoritaria, de modo que separa el archein del prattein a la manera en que los modernos lo hacen (12), sino que también trata de escapar a la responsabilidad inherente a la acción. Finalmente, este acaba aplastado por sus propios muertos, a los que ahora deberá enterrar: oficio que estaba ligado tradicionalmente a las mujeres. El hecho de que Antígona, siendo mujer - y ya habiendo sido descrita como valerosa en Siete contra Tebas de Esquilo, donde anuncia su plan de enterrar a Polinices-, desafíe a Creonte, expresa paradójicamente el sentido de la democracia y de la vida política: el actuar libre en comunidad (12). No parece que la perspectiva de Arendt ni la interpretación de Söderbäck apunten a la abolición del género, sino que su reflexión se orienta más bien a la convergencia de libertad y soberanía, es decir, el reconocimiento del otro como digno de respeto y poseedor de voz en la esfera pública. 


\section{El "Canto al hombre" pone ante nuestros ojos el heCho de que el ser humano CONSTITUYE UNA ENTIDAD LIMITADA EN LOS DOS SENTIDOS DE LA PALABRA, A SABER: QUE ES UN SER QUE EXPERIMENTA LIMITACIONES Y QUE, A SU VEZ, ESTÁ RODEADO DE LÍMITES Y FRONTERAS.}

parte integral de la vida de la polis: ${ }^{13}$ "mas aquel que, por causa de su temeridad, tome parte en lo que no es bueno, quedará proscrito de la ciudad [ápolis]. ¡Que no llegue a sentarse cerca del fuego de mi hogar, ni tenga pensamientos como los míos quien estas cosas realice!" Es por ello que las formas del saber productivo estarían, según su propia naturaleza, dirigidas al bien común de la pólis. Sin embargo, como ya hemos señalado, para Sófocles no parece posible conseguir el bien de la pólis al margen de esa legalidad superior — con cuyos dictados se entreteje la justicia humana - sin caer en la desmesura (hýbris). ${ }^{14}$ De este modo, tal como concluye el coro, ante un individuo temerario que hace lo

13 Esta relación entre el buen y mal uso de la técnica y su vínculo con la polis ha sido también sostenida por Tabachnick (14).

14 El sustantivo hýbris aparece en Antígona en dos ocasiones v. 309 y v. 482, además de dos pasajes donde se usa la forma verbal hybrizeis en indicativo (v. 840) y la forma en infinitivo hybrísein (v. 480). Sin duda, el pasaje más polémico se encuentra en los vv. 480-482, donde jes Creonte quien acusa a Antígona de cometer hýbris! En nuestra lectura, esta acusación, que consideramos "desmesurada", se vuelve sobre el propio Creonte al condenar a muerte —ignorando la figura de Zeus protector del hogar- a su propia sobrina, quien no ha hecho sino cumplir la ley de los dioses al dar sepultura a su hermano. En este sentido, podría quizá sostenerse que no es tanto la desmesura de la hýbris lo que afecta a Antígona, sino más bien la desmesura de su carácter fiero y salvaje, mós en el griego, que, como señala el Corifeo en vv. 471-472, ella ha heredado de su padre. Su incontinencia, si la hay, afecta la forma (el celo apasionado) de su actuar, pero no el fondo de su decisión. No puede, sin embargo, decirse lo mismo de Creonte. que no corresponde (es decir, que hace un mal uso de la técnica), es mejor mantener una prudente distancia procurando no seguir su ejemplo.

\section{EL HOMBRE COMO SER DE LÍMITES}

En definitiva, el "Canto al hombre" pone ante nuestros ojos el hecho de que el ser humano constituye una entidad limitada en los dos sentidos de la palabra, a saber: que es un ser que experimenta limitaciones y que, a su vez, está rodeado de límites y fronteras. Si bien la misión de Sófocles parecía ser la de exponer ambos aspectos por medio de la historia narrada en Antígona, solo la filosofía podría asumir la tarea, no ya de mostrar, sino de analizar y explicar el carácter limitado de la condición humana, lo que en realidad ha hecho abundantemente. A continuación atenderemos precisamente a una de estas contribuciones, la de Aristóteles, quien plantea también una respuesta al desafío intelectual expuesto por los sofistas.

En efecto, para Aristóteles el hombre experimenta limitaciones porque no es todo lo que potencialmente es, no es todo lo que podría ser. Este se despliega en el tiempo y debe ir adquiriendo las perfecciones que le faltan a través de un arduo ejercicio de sus recursos y capacidades. En palabras de Píndaro, debe llegar a ser lo que es (15). Sin embargo, aquí cabe hacer una distinción: no todo despliegue de las propias capacidades trae consigo un 
crecimiento del hombre. Más atrás aludíamos al hecho de que la técnica, en tanto forma de saber orientada a lo productivo y práctico, es ambigua o bidireccional, característica que toma de la misma racionalidad que la origina, puesto que, allí donde esté la racionalidad, existe la posibilidad de darle dos sentidos opuestos (léase, bien o mal, verdad o error). Como enseña Aristóteles, la Medicina puede dañar y curar, y por eso señala que es mejor médico el que daña a su paciente adrede que el que lo hace inadvertidamente..$^{15}$ Ahora bien, es mejor médico, pero también peor hombre.

No sucede lo mismo con los animales, cuya existencia es mucho más sencilla: les basta con seguir el impulso más fuerte. Los animales comparten con el hombre el no ser todo lo que son: es decir, necesitan del cambio para vivir y crecer; pero difieren en el hecho fundamental de que para estos el cambio no constituye un problema, a diferencia de lo que ocurre con el ser humano.

A este respecto, es interesante introducir una breve acotación, desde una perspectiva moderna y posmoderna, sobre la relación entre la vida humana y la animal. En primer término, debe recordarse que no han faltado los autores que han pretendido zanjar esta dificultad

15 Véase, por ejemplo, Ética a Nicómaco (16) (EN) VI 5, 1140b22-23 en relación con Met.(17) IX 2, 1046b4 ss. invitando al hombre a imbuirse en una existencia mucho más sencilla, y de este modo, más cercana a la de los animales. Así, leemos en el Segundo Discurso de Rousseau: " Volved a la primitiva inocencia, puesto que depende de vosotros; id a los bosques a perder de vista y olvidar los crímenes de vuestros contemporáneos, y no temáis envilecer a vuestra especie renunciando a sus luces por renunciar a sus vicios!” (18). ${ }^{16}$

Pero ideas como las expresadas por Rousseau, además de tener una larga historia, han tenido una infinidad de repercusiones hasta nuestro siglo. No obstante las diferencias históricas, se trata en todos los casos de movimientos que tienen en común su carácter reaccionario (20). Efectivamente, en todos es posible observar una aversión permanente ante la creciente complejidad del mundo civilizado. Así, en el campo de la medicina son hoy frecuentes las propuestas terapéuticas que apuestan por una curación "natural” en contra de la medicina tradicional, de la que desconfían. Otro tanto sucede con los intentos actuales de eliminar por completo las fuentes habituales de energía, la vida en las ciudades o los sofisticados instrumentos de la economía. Todos estos empeños tienen en común la búsqueda de una sencillez originaria y la desconfianza frente a la sofisticación de las formas actuales de racionalidad.

16 Más adelante, en todo caso, matizó estas ideas (19). 
Ahora bien, retomando aquí nuestra reflexión de la mano de Sófocles y Aristóteles, resulta interesante constatar que el autor de Antígona estaba muy lejos de haber sido un reaccionario, puesto que, tal como vimos, sus textos testimonian que admiraba el progreso propio de la racionalidad técnica, aunque sancionándola dentro de unos límites bien precisos: el respeto a la ley humana y divina, junto a una cierta consideración del bien común. Y por otra parte, Aristóteles, de quien nos ocupamos ahora, ha sido el filósofo más relevante entre los que han planteado una vía intermedia entre el progresismo de los sofistas y las posturas reaccionarias. En efecto, este admite que existe una naturaleza y expone la necesidad de obrar conforme a ella. Sin embargo, desde su perspectiva, esta no constituye una realidad cuyo origen pueda descubrirse profundizando "hacia atrás", esto es, remitiéndonos a un pasado primigenio $\mathrm{u}$ originario en un estado salvaje o primitivo, sino que consiste, más bien, en una perfección a la que debemos llegar: "la naturaleza es fin”, leemos en la Política (21).

El hombre, tal como lo indicábamos, es limitado porque no ha desarrollado todas sus potencias. Pero tal limitación no constituye pura negatividad, pues da cuenta del carácter perfectible del ser humano, capaz de desarrollarse tanto a través del lenguaje como del "ágil pensamiento" (vv. 353-354). Ahora bien, que el hombre sea perfectible no significa que cualquier desarrollo fáctico de una posibilidad sea correcto o positivo para el despliegue de lo humano. Existen desarrollos fácticos que pueden constituir, en realidad, una auténtica degradación. Para Aristóteles existen actos que un hombre correcto no debe realizar en ninguna circunstancia y bajo ningún pretexto: "hay quizá cosas a las que uno no puede ser forzado, sino que debe preferir la muerte tras terribles sufrimientos: así, las causas que obligaron al Alcmeón
EL HOMBRE, TAL COMO LO INDICÁBAMOS, ES LIMITADO PORQUE NO HA DESARROLLADO todas sus potencias. Pero tal limitación NO CONSTITUYE PURA NEGATIVIDAD, PUES DA CUENTA DEL CARÁCTER PERFECTIBLE DEL SER HUMANO, CAPAZ DE DESARROLLARSE TANTO A TRAVÉS DEL LENGUAJE COMO DEL "ÁGIL PENSAMIENTO".

de Eurípides a matar a su madre resultan ridículas" (EN III 1, 1110a27-29) (16), leemos en la Ética a Nicómaco. La anécdota a la que hace referencia Aristóteles en el citado pasaje no solo es ilustrativa de su pensamiento ético, sino que, recordando a Sófocles, también podría arrojar claridad con respecto a los fundamentos de la decisión de Antígona. Según cuenta el mito recogido por Apolodoro, ${ }^{17}$ el adivino Anfiarao, padre de Alcmeón, fue forzado por su esposa Erífile a unirse a la expedición contra Tebas, aun cuando él sabía que moriría en esa fatal acción bélica. Anfiarao, consumido por su deseo de venganza, le ordenó a sus hijos, Alcmeón y Anfíloco, que llegado el momento, lo vengaran matando a su madre. Pues bien: esta historia refuerza - con la indeleble impresión que dejan en nosotros las imágenes- la reflexión filosófica del Estagirita. En efecto, aun cuando la acción parricida no obedezca a un mero capricho, esas circunstancias que explican en parte la conducta

17 Apolodoro, Biblioteca Mitológica, 3.6.2 ss. Cfr. voces: “Alkmaion”, en Der neue Pauly, Enzyklopädie der Antike (1996) 507-508; "Amphiaraos", 609; "Eriphyle" (22). 
de Alcmeón, resultan, sin embargo, ridículas cuando se trata de matar a la propia madre.

Es interesante constatar - para efectos del presente artículo - la correspondencia de esta anécdota con Antígona: es precisamente ella quien, al enterrar a Polinices elige la muerte antes que ser forzada a hacer — $\mathrm{O}$ a dejar de hacer- lo que estima como una ley absoluta y divina. Por otra parte, continuando esta línea de reflexión, Aristóteles hace expresa referencia a Antígona en su Retórica, al tratar sobre aquella legalidad no escrita que permite trazar las fronteras entre lo correcto y lo indigno para el hombre:

Común es la ley conforme a la naturaleza. Pues de acuerdo con esta existe algo comúnmente justo e injusto, lo cual todos adivinan, aunque no exista ningún acuerdo común entre unos y otros pueblos, ni pacto alguno; así como se nos presenta Antígona en Sófocles cuando dice que es justo sepultar a Polinices, cuya inhumación estaba prohibida, como quiera que esto es justo por naturaleza, "porque esto no es de ahora, ni de ayer, sino que existió siempre, y nadie sabe de dónde procede" (cf. vv. 456-7) (I 13 1373b4-12) (23).

Por otra parte, en un célebre pasaje de la Ética a $\mathrm{Ni}$ cómaco, Aristóteles señala el fundamento teórico de la concepción según la cual hay acciones que nunca deben realizarse: en efecto, aunque en la vida moral se busque el justo medio entre los extremos viciosos, existen ciertas pasiones y acciones malas en sí mismas y que, por tanto, no admiten un justo medio:

No toda acción ni toda pasión admite el término medio, pues hay algunas cuyo mero nombre implica la maldad, por ejemplo, la malignidad, la desvergüenza, la envidia; y entre las acciones el adulterio, el robo y el homicidio. Todas estas cosas y las semejantes a ellas se llaman así por ser malas en sí mismas, no sus excesos ni sus defectos. Por tanto, no es posible nunca acertar con ellas, sino que siempre se yerra. Y no está el bien o el mal, cuando se trata de ellas, por ejemplo, en cometer adulterio con la mujer debida y cuando y como es debido, sino que, en absoluto, el hacer cualquiera de estas cosas está mal (EN II 6, 1107a9-17) (16).

No podríamos decir, por ejemplo, que torturar niños sea bueno siempre que se haga en el momento, en el lugar y en la forma adecuada, pues, independientemente de las circunstancias (o de la intención) que lo origine, hacerlo será siempre una perversión. Aristóteles no expone un catálogo completo de las acciones de por sí perversas ni ahonda en las razones por las que incluye las que figuran en su texto, ni menos cuál sería, en cada caso, el fundamento que las hace intrínsecamente reprobables. Pero la filosofía posterior sí ha ahondado en tales razones. Usando la terminología moderna, hoy podríamos decir que tales acciones constituyen una lesión de la dignidad humana propia o ajena, en la medida que se cosifica e instrumentaliza una realidad que —en léxico kantiano- constituye un fin en sí misma (24). Es evidente que esta última consideración va más allá de Aristóteles, pero ella no es incompatible —-salvadas las diferencias históricas- con lo que el Estagirita afirmaba. ${ }^{18}$

18 El hecho que nos interesa destacar es que la idea de una justicia que va más allá de los dictados de los poderosos y de los acuerdos entre los hombres, lejos de confinarse a la reflexión de la filosofía griega, vuelve a aparecer reiteradamente en la 
En otro pasaje de la Ética, Aristóteles advierte que no toda justicia es puesta por los hombres, sino que hay una que viene de la naturaleza (16). ${ }^{19}$ Sin embargo, es tarea nuestra conocerla, lo que, sin embargo, no es en absoluto sencillo por la enorme facilidad del hombre para engañarse. En este punto, podemos observar que los criterios de justicia se han secularizado: para Aristóteles ya no se trata simplemente de seguir las normas dadas por los dioses, como en Antígona, puesto que — piensa él— tenemos mucho más cerca de nosotros el criterio de juicio, es decir, el criterio de lo natural. ${ }^{20}$ Con todo, aunque existan cosas buenas y malas por naturaleza, no todos accederán fácilmente a ellas por causa de los malos hábitos y de las pasiones que influyen sobre el juicio moral, desviándolo, esto es, precipitando al hombre en el engaño.

La habilitación para conocer lo bueno y lo malo, entonces, no viene dada primeramente por ciertas disposiciones intelectuales, sino por el talante moral del sujeto. Aristóteles advierte que "es cosa trabajosa ser bueno" (EN II 9, 1109a23) (16), y agrega (con realismo) que "la vida templada y firme no es agradable al vulgo, y menos a los jóvenes" (EN X 9, 1180a18) (16), por lo que "la mayor parte de los hombres obedecen más bien a la necesidad que a la razón, y a los castigos que a la bondad" (EN X9, 1180a4-5) (16). En otras palabras, para juzgar acertadamente en materias morales se requiere

historia del pensamiento y es de la máxima actualidad: por todos, el volumen colectivo (25).

19 EN, V, 7 1134b18-1135a5; cfr. también la referencia aristotélica a Antígona, contenida en Retórica III, 16, 1417a30 ss. (23).

20 Esta idea será recogida por toda una tradición filosofófica, que se ha denominado la "tradición central de Occidente“. Ella se extiende desde Platón y Aristóteles hasta autores contemporáneos como Finnis (26) o Spaemann $(27,28)$.
LA HABILITACIÓN PARA CONOCER LO BUENO Y LO MALO, ENTONCES, NO VIENE DADA PRIMERAMENTE POR CIERTAS DISPOSICIONES INTELECTUALES, SINO POR EL TALANTE MORAL

\author{
DEL SUJETO. AristÓteles ADVIERTE QUE "ES \\ COSA TRABAJOSA SER BUENO".
}

una cierta familiaridad con el bien. En este sentido, el conocimiento del mismo no es independiente de su efectiva realización. A diferencia de la geometría y las demás disciplinas especulativas, las cosas morales no se aparecen de la misma forma a todos los hombres, aunque en su esencia y carácter sean tal y como las ve el virtuoso: "Las cosas valiosas y agradables son aquellas que le aparecen como tales al hombre bueno" (EN X $6,1176 \mathrm{~b} 25-26)$ (16), y, en materias morales, "se considera que lo verdadero es lo que le parece al hombre bueno [spoudaios]" (EN X 5, 1176a16) (16). Si esto es así, resulta perfectamente posible que haya individuos que gocen con lo que desagrada al virtuoso, porque no tienen la misma disposición de juicio: “y si las cosas que le molestan [al hombre bueno] le parecen agradables a alguien, no es sorprendente, pues en los hombres hay muchas corrupciones y vicios" (EN X 5, 1176a20-21) (16). De esta manera, Aristóteles resuelve el problema de la ambigüedad de la técnica en términos éticos. En efecto, si bien esta no se basta a sí misma - porque puede ser dirigida hacia el mal- el hombre pleno, el virtuoso, sabrá acertar, de modo que encontrará con seguridad la forma de orientarla tanto hacia el bien del individuo como hacia el bien de la sociedad, que para él debieran 
coincidir —al menor en principio- - Esto mismo se aplica para las ciencias. ¿Supone esto menospreciar la necesidad de que existan mecanismos institucionales que ayuden a poner coto a la mala utilización del poder técnico, científico o político? Este menosprecio no podría atribuirse a Aristóteles, quien en la Política se ocupa en buena medida de precisar el modo y la forma de este tipo de ayudas institucionales. Sin embargo, su pensamiento ético no podría otorgarles un estatuto superior al de meros refuerzos o apoyos que no pueden reemplazar lo que solo consigue la voluntad del hombre, a saber: el bien moral y la verdad.

\section{CONSIDERACIONES FINALES}

El surgimiento de esa primera forma de ilustración que supuso la irrupción de los sofistas (si bien es posible encontrar antecedentes anteriores), ${ }^{21} \mathrm{y}$ el consiguiente proceso de secularización que se dio en la Atenas del Siglo de Oro, significó múltiples y complejas transformaciones en el pensamiento y en la sociedad griega que se vieron reflejadas en la literatura y en la filosofía. Una sensación de crisis, tanto en lo político como en lo moral, resulta manifiesta en muchos de los escritos de Platón, Aristóteles, pero también en Aristófanes, Sófocles o Eurípides. El problema de la técnica, su lugar y valoración al interior del individuo y la sociedad no fue la excepción. En efecto, en el contexto de la Atenas de los

21 Bruno Snell, en un texto clásico, argumenta persuasivamente acerca del surgimiento de la individualidad en los líricos griegos; por otra parte, no pocos clasicistas han prestado atención a las crecientes formas de subjetivización que ya se observan en Hesíodo, quien en su Teogonía (v. 22) introduce, por primera vez en la literatura griega, su propio nombre como autor. Jaeger se refiere a esto como "la nueva aparición de lo subjetivo" (29). Cfr. Jaeger (30). siglos V y IV a. C., resulta de gran interés constatar las similitudes, pero también las diferencias, entre el planteamiento que encontramos en la Antígona de Sófocles y Aristóteles. En ambos hay una admiración irrestricta por la potencialidad propia y singular del hombre, por aquello que nos especifica por sobre los animales. Así lo hacía ver el coro de Antígona: "Muchas cosas hay admirables, pero ninguna más admirable que el hombre" (v. 332-333). Esta confianza puesta en el perfeccionamiento de aquello que le es propio al hombre, no los conducía, sin embargo, a un optimismo ciego e ilusorio respecto del progreso humano, como sí puede observarse en los sofistas. Ambos autores, Sófocles y Aristóteles, si bien cada uno a su modo, comprenden perfectamente que la racionalidad humana, a diferencia de las potencias irracionales cuyo movimiento es siempre unilateral (p. ej., la satisfacción del instinto), puede causar efectos contrarios. Es decir, allí donde interviene la inteligencia (práctica, productiva o teorética), ella puede causar un efecto (el bien) o su contrario (el mal) (17). ${ }^{22}$ Por ello, la bondad de nuestras decisiones no depende de una aplicación mecánica, y por ende irracional, de ciertas reglas, cuyo conocimiento esté al alcance de cualquiera que tenga la inteligencia suficiente para consultar y entender los libros adecuados, sino de una larga y paciente tarea de formación del carácter, que empieza muchos años antes del momento en que hay que tomar la decisión que aquí y ahora nos compromete. Por otra parte, es llamativo constatar que ambos autores piensan que el uso adecuado que un individuo pueda hacer de esa habilidad

22 Cf. IX, 2, 1046b 2 ss.: "Por eso todas las artes, es decir, las ciencias productivas, son potencias [...] Y todas las potencias racionales, ellas mismas, se extienden a ambos contrarios, mientras que las irracionales son cada una de un contrario solamente, por ejemplo, lo caliente solamente puede calentar, mientras que la medicina puede producir la enfermedad y la salud". 
práctica (o productiva) contiene una consideración o referencia hacia la pólis, y la sociedad en su conjunto, que no puede ser pasada por alto. La técnica, en este sentido, no consistiría simplemente en la ampliación de una capacidad individual, sino que poseería, por su propia naturaleza, una dimensión política (acerca del bien común) que está llamada a respetar. Dado que el hombre, en ambos autores, es naturalmente entendido como un animal político, la técnica, que incide en las posibilidades de dominio del hombre (individual), forzosamente tiende por su propio dinamismo interno al bien de la pólis en su conjunto. Por eso, solo quien honra las leyes de la tierra y de los dioses, participando con justicia del gobierno de la pólis, podrá discernir lo que es adecuado o recto, y llegará así a ser honrado por sus pares (hupsípolis). ${ }^{23}$

Por otra parte, no es difícil establecer ciertas diferencias entre sus planteamientos. La más importante, sin duda, tiene que ver con un creciente proceso de secularización o de inmanentización de la ley. En Aristóteles, tanto el discernimiento acerca de lo "justo", cuando está referido a la práxis moral, como el de lo "adecuado”, que alude a la técnica entendida como "disposición productiva acompañada de razón verdadera” (EN, VI, 4, 1140a 20) (16), corresponden a formas de deliberación racional que versan sobre aquellas cosas que — a diferencia de la ciencia- pueden ser de otra manera. Aristóteles no

23 Que el arte o la técnica (téchnē) posee también para Aristóteles una consideración comunitaria y no solo individual puede verse, por ejemplo, en el conocido pasaje de Metafísica (17) I, 1, $981 \mathrm{~b} 11$ ss., donde distingue entre artes con un fin utilitario y otras que no. Aristóteles, en un tono muy similar al de Sófocles, señala que quien descubre nuevas artes es "admirado por la humanidad, no solo porque alguno de sus inventos resultara útil, sino como hombre sabio que descollaba entre los demás". recurre, como sí lo hace Sófocles, a la ley divina (Díke o Thémis) como fundamento o metro último del actuar humano, sino que nos remite a la razón natural del hombre y al modo de ser de las cosas mismas.

Aristóteles, por ello, sin negar la ley divina, opera una naturalización o secularización fundamental que coincide, no obstante, con el gran autor trágico tanto en su admiración frente al progreso que posibilita la técnica, como en su afirmación central de que el poder y el dominio que establece la técnica no deben ser nunca entendidos como "autónomos", esto es, como capaces de dictarse a sí mismos su propia ley. El saber técnico es "heterónomo", puesto que ha de mantener siempre en vista aquello que perfecciona al individuo y a la sociedad en su conjunto. De ahí que el coro de Antígona nos advierta que "aquel que, por causa de su temeridad, tome parte en lo que no es bueno, quedará proscrito de la ciudad [será ápolis]. ¡Qué no llegue a sentarse cerca del fuego de mi hogar, ni tenga pensamientos como los míos quien estas cosas realice!" (vv. 332-375).

\section{REFERENCIAS}

1. Guthrie WKC. A History of Greek Philosophy: Volume 3, The Fifth Century Enlightenment. Cambridge: Cambridge University Press; 1969. 560 p.

2. Heidegger M. Introducción a La Metafísica. Barcelona: Gedisa; 2012. 192 p.

3. Patočka J. Kunst und Zeit: Kulturphilosophische Schriften. Stuttgart: Klett Cotta Verlag; 1987. 610 p.

4. Zink N. Antigone Griechisch/Deutsch. Stuttgart: Reclam; 1981.

5. Angier TPS. Technē in Aristotle's Ethics crafting the moral life. London, New York: Continuum; 2010. viii+176 p. 
6. Vigo A, Pinkler L. Traducción, introducción y notas. Antígona. Buenos Aires: Biblos; 1994.

7. Platón. Teeteto. Buenos Aires: Losada; 2006. 260 p.

8. Aristofanes. Asambleístas. Buenos Aires: Losada; 2010.

9. Platón. Protágoras - Gorgias - Carta séptima. Madrid: Alianza Editorial; 2015. 320 p.

10. Pinkler L. El problema de la ley en la "Antígona” de Sófocles. Pers Derecho Rev Fundam Inst Juríd Derechos Hum. 1998;(39):165-72.

11. Golder W. Hippokrates und das Corpus Hippocraticum: eine Einführung für Philologen und Mediziner. Würzburg: Königshausen \& Neumann; 2007. 254 p.

12. Söderbäck F. Impossible Mourning: Sophocles Reversed. Philos Top. 2011;39(2):165-81.

13. Arendt H. The human condition, 2nd ed. Chicago: University of Chicago Press; 1998. 349 p.

14. Tabachnick DE. Techne, Technology, and Tragedy: Techné Res Philos Technol. 2004;7(3):90-111.

15. Píndaro. Odas y fragmentos. Olimpicas, Piticas, Nemeas, Istmicas, Fragmentos. Madrid: Gredos; 1984. 386 p.

16. Aristóteles. Etica a Nicómaco. Madrid: Centro de Estudios Constitucionales; 2002. 348 p.

17. Aristóteles. Metafísica. Madrid: Gredos; 1998. 884 p.

18. Rousseau J-J. Diskurs über die Ungleichheit $=$ Discours sur l'inégalité. Paderborn: F. Schöningh; 1984.
19. Rousseau J-J. Rousseau juge de Jean Jacques, Troisième dialogue. Oeuvres complètes de J J Rousseau. Paris: Pléiade; 1976.

20. Inciarte F. Reflexiones sobre el republicanismo. Lib Repub Ens Filos Política; 2001.

21. Aristóteles. Política. Madrid: Centro de Estudios Constitucionales; 1989.

22. Apolodoro. Biblioteca mitológica. Madrid: Alianza Editorial; 2004. 312 p.

23. Aristóteles. Retórica. Madrid: Gredos; 2007.

24. Kant I. Grundlegung zur Metaphysik der Sitten. Berlin: Gruyter; 1903.568 p.

25. George RP. In defense of natural law. Oxford - New York: Clarendon Press; 1999. 343 p.

26. Finnis J. Natural Law and Natural Rights, 2nd ed. Oxford New York: Oxford University Press; 2011. 494 p.

27. Spaemann R. Zur Kritik der politischen Utopie: Zehn Kapitel politischer Philosophie. Stuttgart: Klett-Cotta/J. G. Cotta’sche Buchhandlung Nachfolger; 1977.

28. Spaemann R. Moralische Grundbegriffe. 2. Auflage. München: Beck; 1983.

29. Snell B. The discovery of the mind; the Greek origins of European thought. Oxford: Basil Blackwell; 1953. 323 p.

30. Jaeger W. La teología de los primeros filósofos griegos. México, D.F.: Fondo de Cultura Económica; 2003. 265 p 